\title{
Characterization and Valorization of Dietary Fibre Concentrate from Parthenocarpic Date Fruits
}

\author{
Hammadi Hamza, Monia Jemni, Ali Bazmi, Tarek Tombari, and Kameleddine Nagaz
}

\section{ABSTRACT}

Parthenocarpic date fruits are good sources of antioxidant and fibre, which could be changed into valuable by-products. There is no attempt to use it in technological processes and could provide a natural additive to enhance the quality of the product. In this study, fibre concentrate from partenocarpic dates (FCPD) was extracted, dried, and characterized. Two drying techniques, namely oven and freeze drying, were carried out, and then the FCPD were characterized. Thereafter, its ability to substitute flour in muffins was studied.

The freeze-drying gave the highest yield of FCPD revealing lignin richness but cellulose and hemicellulose insufficiency. Drying techniques gave similar FCPD WHC and OHC but antioxidant capacity was higher in the case of freeze-dried fibre. Electronic microscopy showed that the more FCPD was introduced in the flour, the more the muffin crumb contained disrupted matrices. This could enhance the muffin freshness by improving the moisture retention. Moreover, although flour substitution by FCPD increased muffin volume and its $\mathrm{OHC}$ value, its WHC, moisture, mineral and sugar contents were not affected. Calorific value, phenol content and antioxidant activity were greater in the case of muffins with $5 \%$ of freezedried FCPD. Sensory analyses showed that fibre-enriched muffins had good scores as the control ones.

In this study, we used oasis raw materials with good source of fibres and antioxidant capacity that could be used in the production of high valueadded foods. Additionally, the research demonstrated that freeze-dried FCPD flour fortification enhances the physicochemical characteristics of the muffin. The parthenocarpic date fruits is an agricultural residue with interested chemical and functional properties that could be undertaken in food process industries.

Keywords: Electron microscopy, Fibre concentrate, Muffin properties, Parthenocarpic dates.

Published Online: May 21, 2021

ISSN: 2684-5199

DOI: 10.24018 / ejbio.2021.2.3.192

H. Hamza*

Arid and Oases Cropping Laboratory,

Arid Area Institute, Medenine, 4119, Tunisia.

(e-mail: hamzapalmier@yahoo.fr)

M. Jemni

Department of Date Technologies, Regional Center for Research in Oasian Agriculture, Tozeur, Degueche 2260, Tunisia.

(e-mail: jemnimonia ${ }^{@}$ yahoo.fr)

A. Bazmi

Arid and Oases Cropping Laboratory,

Arid Area Institute, Medenine, 4119, Tunisia.

(e-mail: ira.bazmi@ ${ }^{@ a h o o . c o m) ~}$

T. Tombari

Department of Food Process Engineering, Higher Institute of Technological Studies, Kebilli 4200, Tunisia.

(e-mail: tarek_tombari@ ${ }^{\circledR}$ yahoo.fr)

K. Nagaz

Arid and Oases Cropping Laboratory,

Arid Area Institute, Medenine, 4119, Tunisia.

(e-mail: kamelnagaz ${ }^{\circledR}$ yahoo.com)

*Corresponding Author

\section{INTRODUCTION}

Date palm fruit is the most important food for millions of people. The fruit development and ripening are a process influenced by several natural factors including, pollination, climate, and genotype. Ripening associated events in date palm fruits lead to developmentally and physiologically regulated changes in colour, texture, flavour, and aroma of fruit [1]. The loss of a good pollination process provokes significant losses to both farmers and consumers alike because the unpollinated fruits are not profitable due to their size, texture, and sugar content. Indeed, during the last decade, many pollination processes have not been carried out at the best time or under ideal conditions. This is due to many reasons, but the main causes are climate change and the absence of sufficient amounts of the best pollen. As a result, the amount of non-pollinated dates (without seed or parthenocarpic) increased, thus decreasing the number of pollinated dates (seeded fruits) causing a major economic problem [2]. The parthenocarpic dates are smaller and less tasty than the pollinated dates [3].

A previous study [2] have shown that the characteristics of the parthenocarpic dates of the Deglet Nour variety could be developed due to their chemical, functional and technological characteristics. This research work concluded that these nonpollinated dates were chemically and functionally very similar to normal dates even though their soluble sugar content was lower. These seedless fruits have characteristics that are difficult to consume fresh due to their astringency, and they are rather more suited to industrial applications. They are very rich in polyphenols and insoluble polysaccharides which are the main components of the dietary fibre.

On the other hand, to promote a healthier diet, the food industry frequently focuses on the production of reduced fat/sugar/energy foods with a sensory quality that is comparable to that of conventional products [4]. For example, although quick bread muffins are popular breakfast with high consumer acceptance, they are high in sugar and fat 
Therefore, several attempts have been made to increase their nutritional value by replacing sucrose with highly intensive sweeteners or by incorporating dietary fibre.

The objective of the present research work is to extract and characterize the fibre concentrates of the parthenocarpic dates (FCPD). The extracted FCPDs were used in the food sector as flour substitute by the production of the muffins added by these fibres. Microstructure, physicochemical, nutritional characteristics were evaluated for these muffins to justify the use of FCPD as a dietary supplement.

\section{MATERIALS AND METHODS}

\section{A. Samples}

Date palm fruits cv. Deglet Nour were obtained from the continental oases of the southern Tunisia. Up to $5 \mathrm{~kg}$ of parthenocarpic fruit were collected at the full ripeness, sliced, and kept at $-20{ }^{\circ} \mathrm{C}$ in sealed polyethylene bags until processing.

\section{B. Fibre Extraction}

The fibres were extracted according to Borchani et al. [5]. The mixture of date paste and water (1:6) was maintained at $70{ }^{\circ} \mathrm{C}$ for 15 minutes and then filtered in order to separate the insoluble residues. These operations were repeated seven times until the removal of all sugars. Fibre extracts were dried by two different techniques, namely by lyophilisation (HETO, FD8-SS, Namur, Belgium) and oven at two different temperatures $60{ }^{\circ} \mathrm{C}$ and $70{ }^{\circ} \mathrm{C}$. After being dried, fibres were milled in a grinder (7000 rpm, $1 \mathrm{~min})$ and preserved at $4{ }^{\circ} \mathrm{C}$.

\section{Fibre Composition}

Samples were analysed for contents of cellulose, hemicelluloses, and lignin. Acid detergent fibre (ADF) and lignin (ADL) were determined according to the methods of Van Soest et al. [6] using a fibre Analyser (Velp Scientifica). Hemicelluloses and cellulose were calculated by subtracting ADF from NDF and ADL from ADF, respectively [7].

\section{Water and Oil Holding Capacities (WHC and OHC) of FCPD}

About 100mg FCPD were added to $10 \mathrm{ml}$ of distilled water in a $50 \mathrm{ml}$ centrifuge tube and stirred overnight. Then a centrifugation at $14000 \mathrm{~g}$ for $20 \mathrm{~min}$ was done and the supernatant was carefully eliminated. WHC was expressed in $\mathrm{ml}$ of water / gram of the sample [8]. Oil holding capacity (OHC) of FCPD was measured by adding $15 \mathrm{ml}$ of sunflower oil to the concentrate of date fibres in a $50 \mathrm{ml}$ centrifuge tube. The content was stirred overnight then the tubes were centrifuged at $16000 \mathrm{~g}$ for $25 \mathrm{~min}$. OHC was expressed in grams of oils held by one gram in a sample [9].

\section{E. Determination of the Fibre Antiradical Activity}

FCPD antioxidant activity was assessed as described by Fuentes-Alventosa et al. [10]. Between 3 and 14mg of diluted FCPD was placed in eppendorf tube (dilution were done with cellulose as an inert material), and the reaction was started by adding $1.5 \mathrm{ml}$ of the $\mathrm{DPPH} \bullet$ reagent. Centrifugation was done after $30 \mathrm{~min}$ of stirring. The absorbance of the cleared supernatants was measured at $480 \mathrm{~nm}$. Both antioxidant activities were expressed as millimoles of Trolox equivalent antioxidant capacity per kilogram of the sample by means of a dose-response curve for Trolox.

\section{F. Muffin flour Substitution by FCPD}

A quantity of $140 \mathrm{~g}$ of sugar and $180 \mathrm{~g}$ of sunflower oil were mixed using a blender. Later, $5 \mathrm{~g}$ of yeast, $170 \mathrm{~g}$ of wheat flour and $180 \mathrm{~g}$ of eggs were added and mixed. After 20 minutes, $40 \mathrm{~g}$ of the dough were placed on a cake paper and the cooking was done at $200^{\circ} \mathrm{C}$ for 20 minutes. The cooled muffin was put into plastic bags for further analysis [11]. For muffins enriched with FCPD, wheat flour was replaced by the different FCPDs in proportions of 2.5 and $5 \%$ [4].

\section{G. Muffin Characterization}

The determination of muffins volume was realized according to the rapeseed displacement method. For cellular crumb structure description, the fresh muffins were cut, and images of the surface were captured and converted into greyscale with threshold and contrast enhancement. Concerning the microstructure of muffins, it was investigated by Scanning Electron Micrograph, SEM (Thermo Scientific Q250). The samples sections were mounted on metal stub using double-sided tape and the accelerating voltage of electrons ultrafine beam was $30 \mathrm{kV}$. The images of the sample surfaces were viewed at magnification levels of 40-300×.

The WHC and the OHC were measured as described in the FCPD part. The samples of the different formulations were analysed for moisture by freeze drying during $72 \mathrm{~h}$. The dry residues were used for the analysis of protein and ash. Protein content was determined by the Kjeldahl method, applying a factor of 6.25 to convert the total nitrogen into protein content. The sugar content was determined by the method of phenol [12]. Ash was determined according to the AOAC method 923.03 by incinerating samples in a muffle furnace at $550{ }^{\circ} \mathrm{C}$ to white ash. The lipid content was calculated as follow: $100-$ (protein + carbohydrate + ash + moisture $)$ [13] The energy values were obtained using the factors of 4, 9, and $4 \mathrm{Kcal} / \mathrm{g}$ for protein, fat, and sugar, respectively.

Total polyphenol content was quantified according to the Folin-Ciocalteu spectrophotometric method, using gallic acid as a reference standard. Aliquots of $20 \mu 1$ of each liquid fraction were dosified in triplicate, and $100 \mu \mathrm{L}$ of Folin-Ciocalteu phenol reagent $(0.2 \mathrm{M})$ was added to each tube and mixed. Afterward, $80 \mu \mathrm{l}$ of $\mathrm{Na}_{2} \mathrm{CO}_{3}(75 \mathrm{~g} / \mathrm{L})$ was added and mixed well. A microplate reader (iMark, BioRad) was set at $655 \mathrm{~nm}$, and the absorbance was measured after 6 min. The results were expressed as gallic acid (GA) equivalents (mg/100 g FW). Soluble antioxidant activity was determined by the DPPH $\bullet$ method [14], ten $\mu$ l of ethanol soluble fraction was added to $190 \mu \mathrm{l}$ of $\mathrm{DPPH} \cdot$ $(3.8 \mathrm{mg} / 50 \mathrm{~mL}$ methanol), after $30 \mathrm{~min}$ in obscurity, the absorbance was measured at $480 \mathrm{~nm}$. Antioxidant activities were expressed as mmol Trolox equivalent antioxidant capacity / $\mathrm{kg}$ of the sample by means of a dose-response curve for Trolox.

\section{H. Muffin Sensory Analysis}

Primary sensory analysis was conducted by 30 panelists and they are informed about muffin fibre enrichment but not about the nutritional and/or functional benefits. Muffins were evaluated on the basis of acceptability of their colour, texture, flavour, odour and general qualification by a 9-point scale 
where 9 means most liked and 1 most disliked. The samples were placed on white plate and were identified with random numbers.

\section{Statistical Analysis}

Results were expressed as the mean value from triplicate determinations \pm standard deviation. The studied parameters were analysed separately by ANOVA with post-hoc SNK comparisons. Hierarchical cluster analysis was performed using the Euclidean distance. A principal component analysis (PCA) was applied to assess relationships between the physico-chemical data of the muffin samples. The statistical program was SPSS 16.0 for Windows Release 16.0.0 (Sep 13, 2007). Heatmap of muffin sensory evaluation was done by Visual Paradigm international (Online Diagrams) (2019).

\section{RESULTS}

FCPDs obtained by different drying methods showed different aspects (Fig. 1 A, B and C). Fibres resulting from freeze drying were whitish and exhibit a totally different appearance than oven drying fibres. The freeze drying gave a higher yield $(8.6 \%)$ than the other drying techniques, but the difference was not significant (Table I). Hemicellulose content was around $10 \%$ with no significant difference between the three types of drying. The freeze-dried FCPD showed lower cellulose content $(16.64 \%)$ compared to oven drying at $60{ }^{\circ} \mathrm{C}$ and at $70^{\circ} \mathrm{C}$, giving $20.74 \%$ and $20.21 \%$, respectively Lignin has a higher content with an average of
$27 \%$ with no significant drying effect (Table I).

The WHC of FCPD ranged between 7.75 and $7.92 \mathrm{ml} / \mathrm{g}$ FCPD (Table I). No significant differences were observed between the three types of drying.

For the solubility, non-statistical difference was observed, and the rates ranged between 0.28 and $0.29 \%$. The rehydration of freeze-dried fibre is greater due to the structure of the FCPD being altered less than oven dried material. The $\mathrm{OHC}$ was between 3.87 and $4.03 \mathrm{~g}$ oil/g FCPD. Moreover, drying method did not have any effect on the $\mathrm{OHC}$ values.

The measured antiradical activity of FCPD showed significant differences between the drying methods. Actually, the FCPD given by freeze-drying has higher antioxidant activity (43.32 mmolsTrolox $/ \mathrm{kg}$ ) than that provided by oven drying technique (Table I).

The prepared muffins showed different aspects (Fig. 1 DJ). Indeed, fibre-free muffins had different appearance from other muffins, and they were lighter and with no pores. Fibres addition made colour darker but muffins with lyophilized fibres showed the darkest appearance. Fig. 2 shows the longitudinal cut surface of the muffins. A significant increase of tunnels was observed when the flour was partially replaced with FCPD. The flour replacement with lyophilized FCPD gave more evident cells than those containing oven-dried FCPD. On the other hand, control sample had an average volume of $90.67 \mathrm{ml}$. A significant increase in cake volume was noted with the addition of FCPD except in the case of FCPD_70 ${ }^{\circ} \mathrm{C}(5 \%)$ (Table II).

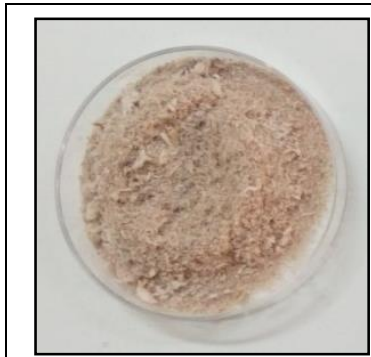

A

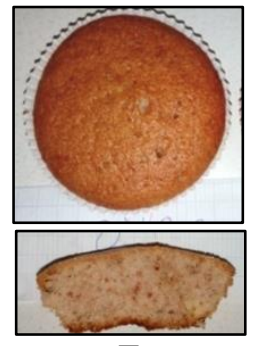

$\mathbf{F}$

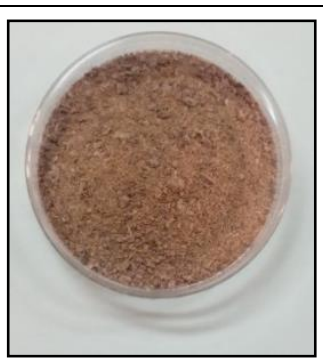

B

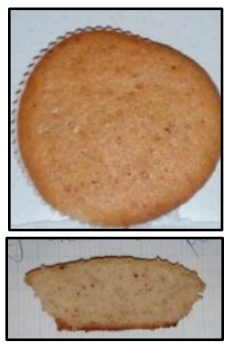

G

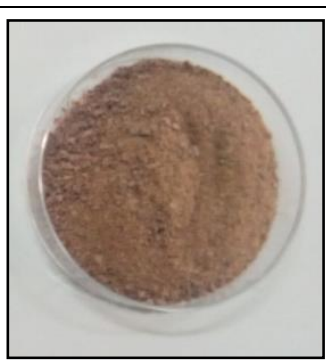

$\mathbf{C}$

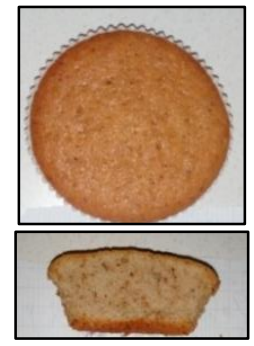

H

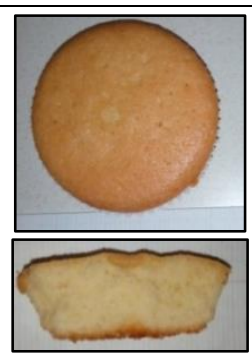

D

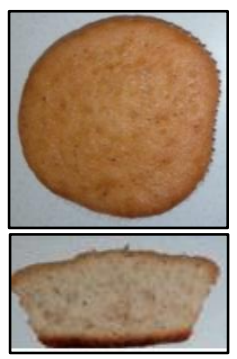

I

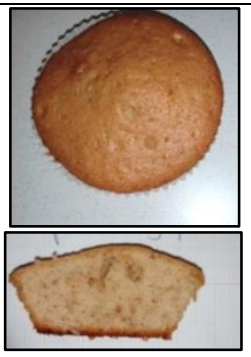

$\mathbf{E}$

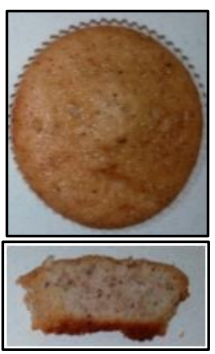

$\mathbf{J}$

Fig. 1. Fibre concentrates parthenocarpic date (A: Freeze dried, B: Oven dried at $60^{\circ} \mathrm{C}, \mathrm{C}:$ Oven dried at $70{ }^{\circ} \mathrm{C}$ ) and different types of formulations muffins (D: Control, E: with $2.5 \%$ freeze dried fibre, F: with $5 \%$ freeze dried fibre, G: with $2.5 \%$ oven dried fibre at $60{ }^{\circ} \mathrm{C}$, $\mathrm{H}$ : with $5 \%$ oven dried fibre at $60{ }^{\circ} \mathrm{C}$, I: with $2.5 \%$ oven dried fibre at $70{ }^{\circ} \mathrm{C}$, J: with $5 \%$ oven dried fibre at $70{ }^{\circ} \mathrm{C}$ ).

TABLE I: YIELDS, COMPOSITION, HOLDING CAPACITIES AND ANTIOXIDANT ACTIVITY OF DIFFERENT FCPDS

\begin{tabular}{cccc}
\hline Drying & Freeze-drying & Oven_60 ${ }^{\circ} \mathrm{C}$ & Oven_70 ${ }^{\circ} \mathrm{C}$ \\
\hline Yield $(\% \mathrm{MF})$ & $8.6( \pm 0.80) \mathrm{a}$ & $7.76( \pm 0.63) \mathrm{a}$ & $7.54 \pm(0.65) \mathrm{a}$ \\
Hemicellulose & $10.77( \pm 1.51) \mathrm{a}$ & $9.17( \pm 0.91) \mathrm{a}$ & $9.51( \pm 1.22) \mathrm{a}$ \\
Cellulose & $16.64( \pm 1.22) \mathrm{b}$ & $20.74( \pm 1.62) \mathrm{a}$ & $21.21( \pm 2.40) \mathrm{a}$ \\
Lignin & $26.75( \pm 3.26) \mathrm{a}$ & $27.18( \pm 2.94) \mathrm{a}$ & $27.76( \pm 3.25) \mathrm{a}$ \\
WHC (ml water/g) & $7.92( \pm 1.22) \mathrm{a}$ & $7.85( \pm 1.80) \mathrm{a}$ & $7.75( \pm 1.31) \mathrm{a}$ \\
Sol \% & $0.29( \pm 0.01) \mathrm{a}$ & $0.28( \pm 0.04) \mathrm{a}$ & $0.28( \pm 0.03) \mathrm{a}$ \\
OHC (ml Oil/g) & $4.03( \pm 0.56) \mathrm{a}$ & $3.87( \pm 0.75) \mathrm{a}$ & $3.95( \pm 0.38) \mathrm{a}$ \\
Antioxidant activity* & $43.32( \pm 3.45) \mathrm{a}$ & $43.21( \pm 2.65) \mathrm{a}$ & $35.08( \pm 1.25) \mathrm{b}$ \\
\hline *mmolsTrolox/kg. & & &
\end{tabular}


TABLE II: Volume, Density, Holding CAPACITIES AND CHEMICAL COMPOSITION OF MuFFINS

\begin{tabular}{|c|c|c|c|c|c|c|c|}
\hline \multirow{3}{*}{ Muffin type } & \multirow{3}{*}{ Control } & \multicolumn{6}{|c|}{ With FCPD } \\
\hline & & \multicolumn{2}{|c|}{ Freeze-drying } & \multicolumn{2}{|c|}{$60^{\circ} \mathrm{C}$} & \multicolumn{2}{|c|}{$70^{\circ} \mathrm{C}$} \\
\hline & & $2.5 \%$ & $5 \%$ & $2.5 \%$ & $5 \%$ & $2.5 \%$ & $5 \%$ \\
\hline Volume (ml) & $90.67( \pm 2.08) \mathrm{c}$ & $97.33( \pm 2.31) \mathrm{a}$ & $95.67( \pm 4.04) \mathrm{ab}$ & $97.67( \pm 2.33) \mathrm{a}$ & $94.507( \pm 2.09) \mathrm{a}$ & $98.00( \pm 3.46) \mathrm{a}$ & $91.00( \pm 5.29) \mathrm{c}$ \\
\hline Density (g/ml) & $0.39( \pm 0.01) \mathrm{ab}$ & $0.36( \pm 0.01) \mathrm{b}$ & $0.36( \pm 0.016) \mathrm{b}$ & $0.36( \pm 0.014) b$ & $0.37( \pm 0.03) \mathrm{ab}$ & $0.36( \pm 0.01) \mathrm{b}$ & $0.40( \pm 0.026) \mathrm{a}$ \\
\hline WHC (mL & $0.95( \pm 0.24) \mathrm{a}$ & $0.97( \pm 0.41) \mathrm{a}$ & $1.06( \pm 0.06) \mathrm{a}$ & $1.33( \pm 0.78) \mathrm{a}$ & $1.04( \pm 0.04) \mathrm{a}$ & $1.11( \pm 0.55) \mathrm{a}$ & $1.10( \pm 0.54) \mathrm{a}$ \\
\hline $\mathrm{OHC}(\mathrm{mL}$ oil/g) & $2.70( \pm 0.39) \mathrm{b}$ & $3.13( \pm 0.88) \mathrm{b}$ & $3.60( \pm 0.67) \mathrm{ab}$ & $4.72( \pm 1.16) \mathrm{a}$ & $2.55( \pm 0.62) \mathrm{b}$ & $3.83( \pm 0.93) \mathrm{ab}$ & $3.99( \pm 0.90) \mathrm{ab}$ \\
\hline Moisture \% & $13.67( \pm 2.2) \mathrm{a}$ & $12.97( \pm 1.25) \mathrm{ab}$ & $12.77( \pm 1.25) \mathrm{ab}$ & $13.02( \pm 2.03) \mathrm{ab}$ & $13.65( \pm 1.85) \mathrm{a}$ & $12.52( \pm 1.74) b$ & $13.52( \pm 1.95) \mathrm{a}$ \\
\hline Ash \% & $1.01( \pm 0.01) \mathrm{a}$ & $0.99( \pm 0.01) \mathrm{a}$ & $1.02( \pm 0.01) \mathrm{a}$ & $0.98( \pm 0.01) \mathrm{a}$ & $0.96( \pm 0.01) \mathrm{a}$ & $1.03( \pm 0.02) \mathrm{a}$ & $1.01( \pm 0.01) \mathrm{a}$ \\
\hline Total sugar & $53.04( \pm 4.29) \mathrm{a}$ & $55.09( \pm 5.82) \mathrm{a}$ & $52.61( \pm 4.17) \mathrm{a}$ & $54.24( \pm 1.40) \mathrm{a}$ & $55.91( \pm 0.24) \mathrm{a}$ & $55.63( \pm 0.51) \mathrm{a}$ & $56.28( \pm 2.77) \mathrm{a}$ \\
\hline Lipid g/100g & $20.62( \pm 2.50) b c$ & $21.18( \pm 2.20) \mathrm{ab}$ & $23.79( \pm 2.90) \mathrm{a}$ & $21.8( \pm 2.10) b$ & $19.47( \pm 1.95) \mathrm{c}$ & $20.72( \pm 3.05) \mathrm{a}$ & $19.15( \pm 2.55) \mathrm{c}$ \\
\hline $\mathrm{Kcal} / 100 \mathrm{~g}$ & $444.38( \pm 40.75)$ & $450.06( \pm 40.88)$ & $463.79( \pm 50.10)$ & $453.00( \pm 40.90)$ & $438.91( \pm 40.50)$ & $449.4( \pm 40.98)$ & $437.63( \pm 50.05)$ \\
\hline
\end{tabular}

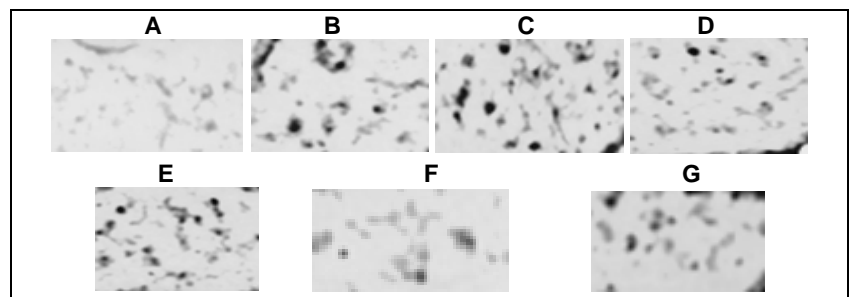

Fig. 2. Cellular structure of the crumb of different types of formulations muffins (A: Control, B: with $2.5 \%$ freeze dried fibre, C: with $5 \%$ freeze dried fibre, D: with $2.5 \%$ oven dried fibre at $60{ }^{\circ} \mathrm{C}$, E: with $5 \%$ oven dried fibre at $60{ }^{\circ} \mathrm{C}$, F: with $2.5 \%$ oven dried fibre at $70{ }^{\circ} \mathrm{C}$, G: with $5 \%$ oven dried fibre at $70{ }^{\circ} \mathrm{C}$ ).

To investigate the detailed structure of muffins, Scanning Electron Microscopy (SEM) was used, and the results are shown in Fig. 3. In the control muffin, starch granules were deformed due to the gelatinization process and implanted in continuous matrix (Fig. 3 A). In Figs. 3 B and C, which are the micrographs of muffins with 2.5 and 5\% FCPD, respectively, the matrices became disrupted, and the starch granules were less observed. The disruption degree of matrices was higher in the micrographs of muffin crumb with 5\% FCPD represented by Fig. 3 C.

Scanning Electron Microscopy (SEM) was used to investigate the detailed structure of muffins, and the results are shown in Fig. 3. In the control muffin, starch granules were deformed due to the gelatinization process and implanted in continuous matrix (Fig. 3 A). In Figs. 3 B and $\mathrm{C}$, which are the micrographs of muffins with 2.5 and $5 \%$ FCPD, respectively, the matrices became disrupted, and the starch granules were less observed. The disruption degree of matrices was higher in the micrographs of muffin crumb with 5\% FCPD represented by Fig. $3 \mathrm{C}$.

WHC values of muffins were between 0.95 and $1.33 \mathrm{ml} / \mathrm{g}$ (Table II) and no statistical difference between muffin types. For $\mathrm{OHC}$, the values ranged between 2.55 and $4.72 \mathrm{ml} / \mathrm{g}$ and increased with the addition of fibres. Holding capacities parameters are very important in determining the nutritional quality of muffins. Although the water retention capacity was not affected, OHC was ameliorated when the fibres were added to the muffins, except when FCPD_60 ${ }^{\circ} \mathrm{C}$ were added at the rate of $5 \%$.

Among the measured components, although ash and carbohydrate content did not show any significant differences (Table II), protein and lipid content showed a significant difference with the addition of FCPD. The addition of fibre decreased the protein content in comparison with the control. Freeze-dried FCPD incorporation at the rate of 5\% increased the lipid content in muffin, and therefore gave the highest calorific power $(463.79 \mathrm{Kcal} / 100 \mathrm{~g})$ (Table II). The muffin enrichment by FCPD increased the phenol content especially for Freeze dried FCPD (Fig. 4). This showed the effectiveness of freeze drying compared to other techniques.

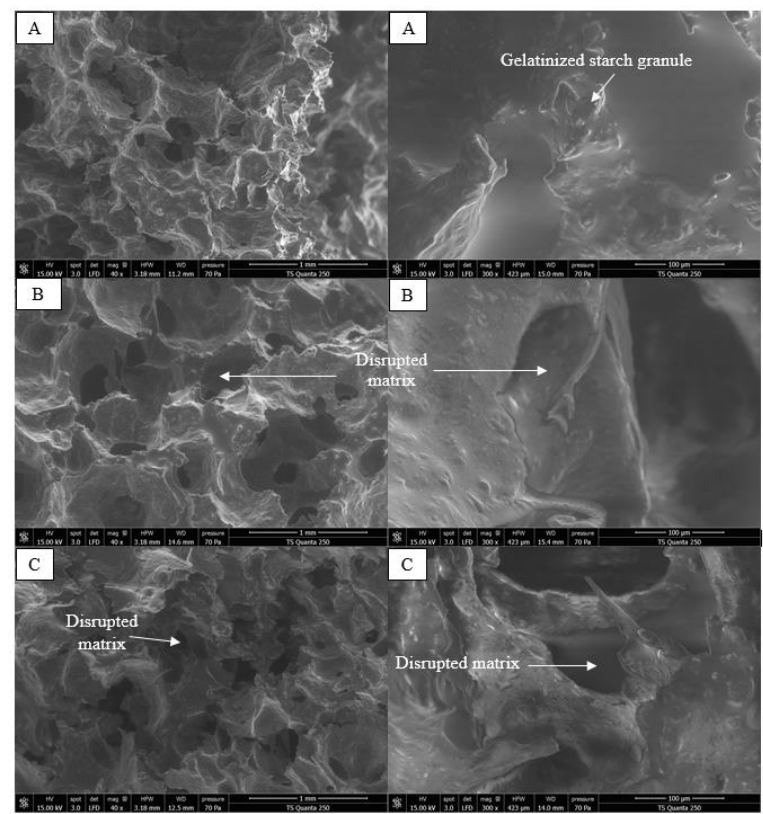

Fig. 3. Scanning electron microscopy (SEM) of different types of formulations muffins (A: Control, B: with $2.5 \%$ oven dried fibre at $60{ }^{\circ} \mathrm{C}$, $\mathrm{C}$ : with $5 \%$ oven dried fibre at $60{ }^{\circ} \mathrm{C}$ ).

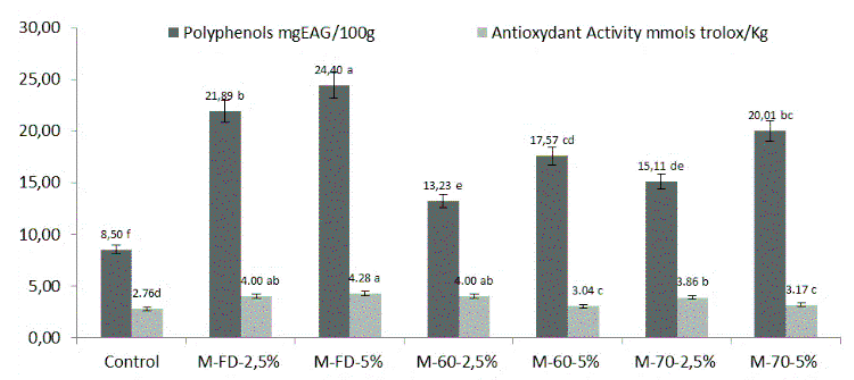

Fig. 4. Phenol content and antioxidant capacity of different types of muffins. M: muffin followed by the fibre drying technique (FD: freeze-dried or at $60{ }^{\circ} \mathrm{C}$ or at $70^{\circ} \mathrm{C}$ ) followed flour substitution percentage $(2.5$ or $5 \%)$.

The results obtained by the hierarchical cluster analysis of all muffin samples considering all parameters except the calorific power are presented in Fig. 5 A. Four main cluster groups were identified: cluster 1 \{control\}, cluster 2 \{Muffins with $2.5 \%$ and $5 \%$ of freeze drying fibre $\}$ and cluster 3 \{Muffin with oven dried fibre\}. As indicated by the linkage distance, the control sample had the largest cluster discrimination compared to that of the other treatments. The samples M-FD-2.5 and M-FD-5 had a shorter cluster distance to the control sample compared to that of the muffin with oven drying fibre. Cluster 3 showed that flour substitution degree by fibre was significant when it was oven dried either in $60{ }^{\circ} \mathrm{C}$ or $70{ }^{\circ} \mathrm{C}$. However, cluster 2 indicated that the freeze drying technique had strongly affected the muffin properties.

The principal component analysis (Fig. 5 B-C) described 
the interrelations of the studied parameters with the muffin's formulations. A strong pattern of differentiation was shown by the first three principal components which explained $82.14 \%$ of the total variation (PCA $1=46.69 \%$ and PCA $2=$ $20.70 \%$, PCA $3=14.74 \%$ ) (Table III). The PCA 1 was highly correlated with volume $(+0.834)$, density $(-0,828)$, moisture $(-0,883)$, protein $(-0,716)$, lipid $(+0,773)$ and antioxidant capacity $(+0,986)$. The PCA 2 was correlated with ash ($0,588)$ and sugar $(+0,860)$. The third axis was defined by WHC $(+0,722)$, OHC $(+0,677)$ and phenol $(-0.668)$ (Table III). In terms of formulations, the control sample was separated with the two first components, so it was characterized by low volume of lipid, antioxidant, and sugar values but high rates of density, moisture, protein, and ash. The muffin enriched by oven-drying fibre $\left(60^{\circ} \mathrm{C}\right.$ and $\left.70{ }^{\circ} \mathrm{C}\right)$ at the rate of $5 \%$ had lower volume, lipid, antioxidant values and ash but with high rates of density, moisture, protein, and sugar. On the other hand, muffin with freeze-drying fibre at the rate of 5\% was characterized by higher volume, lipid, antioxidant and ash content and low density, moisture, protein, and sugar. Muffin with freeze-drying fibre at the rate of $2.5 \%$ was characterized by low WHC and $\mathrm{OHC}$ and high Phenol content.
The primary sensory evaluation is given in Table IV and Fig. 6. There were no significant differences among the samples with and without FCPD substitution for scores of colour, flavour, and general qualification while for texture and odour significant differences were detected. Concerning the texture, the lower score was for the control, the addition of FCPD has ameliorated this parameter by giving pores inside muffins which were appreciated by panellists. The lowest odour value was for muffins with FCPD_60 ${ }^{\circ} \mathrm{C} \_2.5 \%$ and FCPD_70 ${ }^{\circ} \mathrm{C} \_5 \%$.

TABLE III: EIGENVALUES AND COMPONENT OF THE FIRST THREE AXIS OF PCA

\begin{tabular}{|c|c|c|c|}
\hline \multirow{2}{*}{ Component } & \multicolumn{2}{|c|}{ Initial Eigenvalues } & \multirow{2}{*}{ Component Matrix } \\
\hline & $\%$ of Variance & Cumulative $\%$ & \\
\hline 1 & 46.69 & 46.69 & $\begin{array}{c}\text { Volume (+0.834); Density } \\
\text { (-0.828); Moisture (-0.883); } \\
\text { Protein (-0.716); Lipid } \\
\text { (+0.773); Antioxidant (+0.986) }\end{array}$ \\
\hline 2 & 20.70 & 67.39 & Ash (-0.588); Sugar (+0.860) \\
\hline 3 & 14.74 & 82.13 & $\begin{array}{c}\text { WHC (+0.722); OHC }(+0.677) ; \\
\text { Phenol }(-0.668)\end{array}$ \\
\hline
\end{tabular}

TABLE IV: PRIMARY SENSORY EVALUATION OF DIFFERENT TYPES OF MUFFINS

\begin{tabular}{|c|c|c|c|c|c|c|c|}
\hline \multicolumn{3}{|c|}{ Muffin type } & Colour & Texture & Flavour & Odour & $\begin{array}{c}\text { General } \\
\text { qualification }\end{array}$ \\
\hline \multicolumn{3}{|c|}{ Control } & $7.42( \pm 0.42) \mathrm{a}$ & $7.17( \pm 0.10) \mathrm{b}$ & $7.79( \pm 0.27) a$ & $7.46( \pm 0.12) \mathrm{a}$ & $7.53( \pm 0.19) \mathrm{a}$ \\
\hline \multirow{6}{*}{ 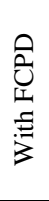 } & & $2.5 \%$ & $7.71( \pm 0.31) a$ & $7.92( \pm 0.18) a$ & $7.63( \pm 0.21) a$ & $7.29( \pm 0.28) \mathrm{ab}$ & $7.79( \pm 0.20) \mathrm{a}$ \\
\hline & Freeze-drying & $5 \%$ & $7.33( \pm 0.25) \mathrm{a}$ & $7.46( \pm 0.10) a$ & $7.38( \pm 0.31) a$ & $7.33( \pm 0.50) \mathrm{ab}$ & $7.50( \pm 0.39) \mathrm{a}$ \\
\hline & & $2.5 \%$ & $7.71( \pm 0.55) \mathrm{a}$ & $7.33( \pm 0.16) \mathrm{a}$ & $7.29( \pm 0.30) \mathrm{a}$ & $6.92( \pm 0.42) c$ & $7.25( \pm 0.22) \mathrm{a}$ \\
\hline & & $5 \%$ & $7.92( \pm 0.65) a$ & $7.45( \pm 0.18) \mathrm{ab}$ & $7.79( \pm 0.19) \mathrm{a}$ & $7.25( \pm 0.19) \mathrm{ab}$ & $7.67( \pm 0.32) a$ \\
\hline & & $2.5 \%$ & $7.58( \pm 0.21) \mathrm{a}$ & $7.54( \pm 0.16) \mathrm{a}$ & $7.79( \pm 0.18) \mathrm{a}$ & $7.63( \pm 0.36) \mathrm{a}$ & $7.75( \pm 0.17) a$ \\
\hline & $70^{\circ} \mathrm{C}$ & $5 \%$ & $7.50( \pm 0.11) \mathrm{a}$ & $7.54( \pm 0.13) \mathrm{a}$ & $7.38( \pm 0.40) \mathrm{a}$ & $6.92( \pm 0.27) \mathrm{c}$ & $7.50( \pm 0.52) \mathrm{a}$ \\
\hline
\end{tabular}

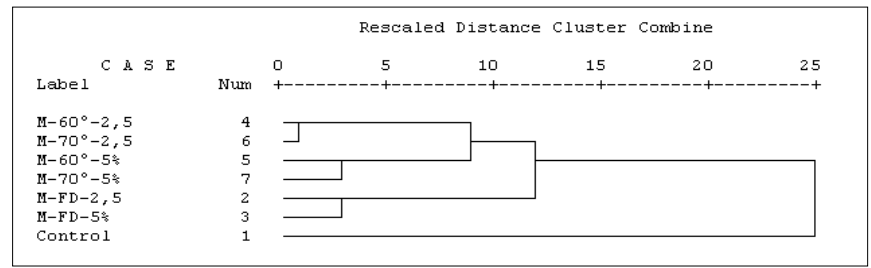

(A)

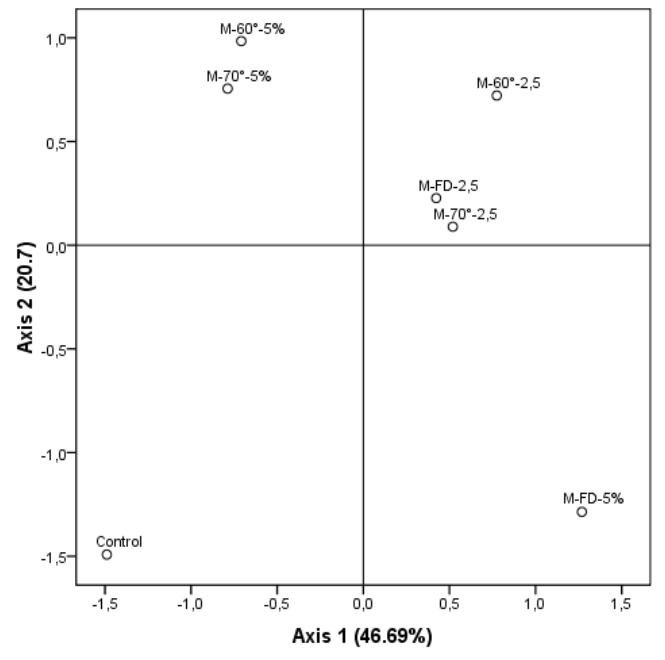

(B)

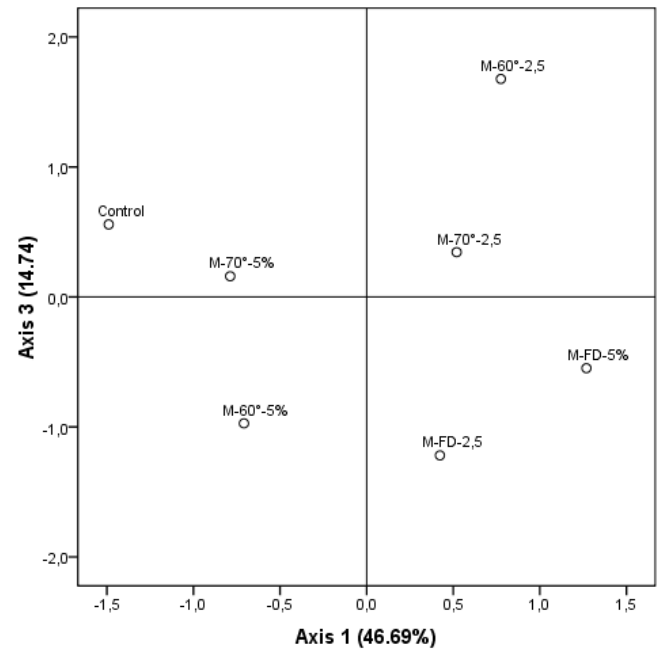

(C)

Fig. 5. Cluster analysis (A) and principal component analysis (B and C) visualizing muffin formulations. M: muffin followed by the fibre drying technique (FD: freeze dried or oven dried at $60{ }^{\circ} \mathrm{C}$ or at $70^{\circ} \mathrm{C}$ ) followed flour substitution percentage $(2.5$ or $5 \%$ ). 


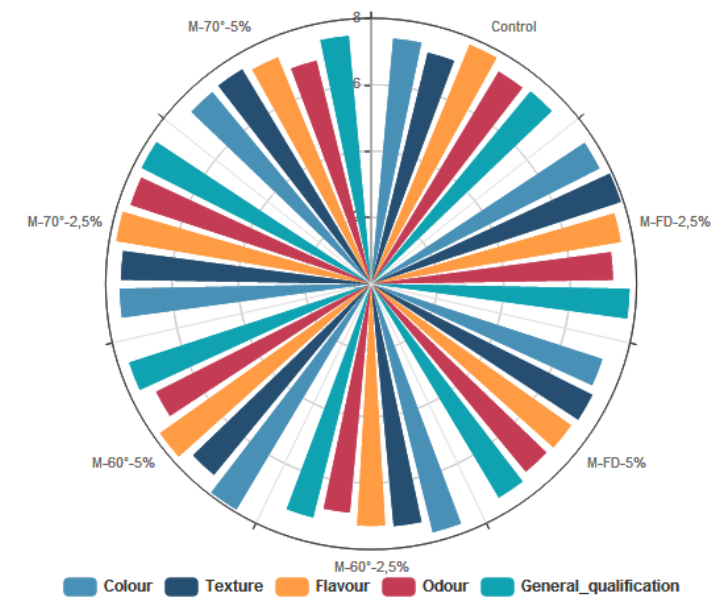

Fig. 6. Primary sensory evaluation of different types of muffins. M: muffin followed by the fibre drying technique (FD: freeze dried or oven dried at $60{ }^{\circ} \mathrm{C}$ or at $\left.70^{\circ} \mathrm{C}\right)$ followed flour substitution percentage $(2.5$ or $5 \%)$.

\section{DISCUSSION}

The aspect of the obtained FCPD was consistent with Nsren [15] who has noticed that hot dehydration causes a change in colour and composition with respect to the fresh material. This result is explained by the fact that drying causes cell damage, which leads to the phenolic substrate to be exposed to the browning enzyme polyphenoloxidase. The FCPD yields were relatively higher than those previously obtained from pollinated dates of the same variety [16]. Compared with other species, FCDP levels was also higher than cereals [17], [18], mango and grapes [19]. The composition of FCDP was in agreement with that obtained by Mrabet et al. [11]. These authors analysed Tunisian varieties and found a percentage of cellulose between 17.0 and $20.5 \%$, while that of hemicellulose between 10.8 and $20.5 \%$.

The WHC of FCPD was lower than that of banana dietary fibre concentrates (9.25-10.52 $\mathrm{g}$ water/g dry matter) [20] and peach dietary fibre concentrates $(9.2-9.3 \mathrm{~g}$ water/g fibre) [4]. According to these authors, the lower values of WHC found in dietary fibre concentrates could be attributed to the lower content of soluble dietary fibre comprising some components in the plant tissue materials having the ability to hold water. Wachirasiri et al. [20] found that drying affected the physical structure of the dietary fibre concentrates by breaking pores which cause the increase in fibre density, and thus reducing WHC. In fact, the high WHC of the FCPD indicated the potentiality to be used as a functional ingredient to avoid the viscosity and texture modification of formulated products [20]. FCPD OHC were similar to those observed in banana peel fibre [20], pear pomace fibre [21] and pollinated date fibre [5], [11]. The holding capacities provide the aliments with important physiological and technological properties. This suggests that FCPD could be used in the formulation of new products with good emulsifying properties. Borchani et al. [22] have investigated the influence of drying temperatures $\left(40{ }^{\circ} \mathrm{C}, 50^{\circ} \mathrm{C}, 60^{\circ} \mathrm{C}\right)$ on the $\mathrm{OHC}$ of date fibre, revealing that the temperature of the high drying did not affect OHC CFDs, which is in agreement with our results. Similar results have been obtained by Lou et al. [23] who reported that high temperatures had not significant effect on OHC. On the other hand, FCPD antiradical activity values were lower than those observed by Hamza et al. [2] who measured the antioxidant capacity in the ethanol insoluble fraction of fresh parthenocarpic fruit.

Flour substitution percentage by FCPD has been realized according to previous results [4], indicating that up to $15 \%$ flour by dietary fibre altered some characteristics of the food products, including the appearance, flavour, texture, and mouth feel, in different ways, depending on the dietary fibre source. For this reason, we have reduced the flour substitution percentages and tested 2.5 and $5 \%$ values. The presence of pores inside muffins has to do with the water holding capacity of fibre. During cooking, the temperature of $200{ }^{\circ} \mathrm{C}$ evaporated the retained water and created pores that gave the texture of enriched fibre muffin [24]. The muffin volume results did not accord with the result pertaining to the decrease of cake volume with the increase in apple pomace levels [25], as well as with the addition of flaxseed powder to muffin [26]. In fact, dough density is influenced not only by the percentage of the added fibre, but also by fibre chemical composition, fibre size, cake formula, gas retention and cake volume [11]. Thus, the results of the cake specific volume in this study may be due to the increased replacement of flour with cellulose, which has been reported to weaken the gluten matrix responsible for retaining gases in baked foods [27], [28].

The SEM of the control muffin was in accordance with the findings obtained by Sowmya et al. [29]. When the FCPDs incorporation level increased, the muffin matrix became more irregular, the starch granules were not totally immersed, and they were observed as detached structures on the matrix surface, which is in agreement with the findings of Pomeranz et al. [30]. Actually, they have reported that the bran particles might interrupt the continuity of the matrix in wheat rye bread dough. Gao et al. [31] attribute these figures to the inhibition of starch gelatinization caused by water competition between different dough compositions.

The use of FCPD may be advisable in products that require emulsifying properties. During muffin processing, a percentage of wheat flour was replaced by FCPD which did not change the moisture which reflect that FCPD have the same water holding capacity as the wheat flour. These results were similar to those obtained when fibres from pollinated dates were added [11] but the addition of $9 \%$ of cactus fibre increased the moisture cake by $32 \%$ [32]. Grigelmo-Miguel et al. [4] have also found that peach-DF muffins were moister than the control ones. According to them, the dietary fibre concentrates avoided water loss during baking due to its high WHC and maintained the freshness of the product. FCDP muffin chemical composition was found to be in accordance with peach-DF muffins [4] and pollinated date-DF ones [11]. However, the substitution of date seed flour hydrolysate $(2.5 \%)$ or date seed flour $(2 \%$ and $5 \%)$ increased the ash contents of muffin [33]. It should be noted that the calculated calorific value does not reflect reality in the human body. In fact, the high capacity to retain the oils by the fibres makes the muffins less calorific than that expected. Several retained lipids are eliminated due to the fibre by the intestinal transit, and they will no longer be available to the body. This is why we think that the calorific value will be lower than that in Table II. 
The phenol richness of our muffins with parthenocarpic date fibres offers a very high nutritional quality. As another source of fibre, flaxseed powder increased the phenolic content of muffin [26]. Indeed, our results showed that muffins with lyophilized fibre $5 \%$ had the highest antioxidant activity of other muffins, the lowest one was for fibre-free muffins. The same effects were observed when other antioxidant fibres were added to bakery products [34], [35]. A good part of the total antioxidant activity of the studied muffin could be attributed to FCPD and revealed its essential physiological function gastrointestinal tract.

Sensory evaluation is in agreement with Grigelmo-Miguel et al [4] which found that panellists considered that muffins with 2, 3, 4 and 5\% peach DF were as acceptable as the control ones. In addition, Talens et al. [36] observed that the addition of orange fibres and the drying method do not affect the acceptability of muffins by panellists. Mrabet et al. [11] proved that the acceptability of a healthy new food depends on several factors and among them, the information and consumers' health consciousness. In this work, as mentioned, panellists were informed about muffin fibre enrichment but not about the nutritional and/or functional benefits.

\section{CONCLUSION}

This study developed new processes for applying parthenocarpic Deglet Nour fruits, a good source of dietary fibre, as improved functional ingredients in bakery. In fact, since the method of fibre drying has an effect on muffin quality, we suggested freeze-drying as the best method thanks to the physicochemical characteristics as compared with oven drying. Fibre freeze-drying is a promising technology to improve the muffin quality while keeping very good physicochemical properties. Furthermore, flour substitution with freeze-drying FCPD with $5 \%$ in muffin is an interesting formulation to be considered to reduce sugar content and increase the content of phenolic compounds of the product and essentially to improve its antioxidant profile. The effect of flour replacement by FCPD was significant on the microstructure of muffin. Indeed, FCPDs were able to create a discontinuous matrix with starch fragments. This matrix is favorable for moisture retention, which could enhance the muffin's freshness.

\section{ACKNOWLEDGMENT}

We extend our thanks to Mrs Leila Mahfoudhi, teacher of English in the Faculty of Sciences of Sfax, for proofreading and polishing the language of the manuscript.

\section{REFERENCES}

[1] S.M.H. Mortazavi, F. Azizollahi, N. Moalemi, "Some Quality Attributes and Biochemical Properties of Nine Iranian Date (Phoenix dactylifera L.) Cultivars at Different Stages of Fruit Development," Int. J. Hortic. Sci. Technol., vol. 2, no. 2, pp.161-171, October 2015 https://dx.doi.org/10.22059/ijhst.2015.56433.

[2] H. Hamza, A. Mrabet, A. Jiménez-Araujo, "Date palm Parthenocarpic Fruits (Phoenix dactylifera L.): Chemical Characterization, Functional Properties and Antioxidant Capacity in Comparison with Seeded Fruits," Scientia Horticulturae, vol. 211, pp. 352-357, November 2016. https://doi.org/10.1016/j.scienta.2016.09.031.
[3] A.A. Jaradat. "Biodiversity, genetic diversity, and genetic resources of date palm," In: Date Palm Genetic Resources, Cultivar Assessment, Cultivation Practices and Novel Products, J.M. Al-Khayri, M.J. Shri, V.J. Dennis, (eds.), Springer, Dordrecht, 2014, pp. 19-71. https://doi.org/10.1007/978-94-017-9694-1_2.

[4] N. Grigelmo-Miguel, E. Carreras-Boladeras, O. Martin-Belloso, "Development of high-fruit-dietary-fiber muffins," Eur. Food Res. Tech., vol. 210, pp. 123-128, December 1999. https://doi.org/10.1007/s002170050547.

[5] C. Borchani, S. Besbes, C. Blecker, M. Masmoudi, R. Baati, H. Attia, "Chemical properties of 11 date cultivars and their corresponding Fiber extracts”. Afr. J. Biotechnol., vol. 9, 4096-4105, 2010.

[6] P.J. Van Soest, J.B. Robertson, B.A. Lewis, J. Dairy, "Methods for dietary fiber, neutral detergent fiber, and nonstarch polysaccharides in relation to animal nutrition". J. Dairy Sci., vol. 74(10), 3583-3597, October 1991. https://doi.org/10.3168/jds.S0022-0302(91)78551-2.

[7] M. Rinne, S. Jaakkola, P. Huhtanen, "Grass maturity effects on cattle fed silage-based diets. 1. Organic matter digestion, rumen fermentation and nitrogen utilization," Anim. Feed Sci. Tech., vol. 67, pp. 1-17, June 1997. https://doi.org/10.1016/S0377-8401(96)01141-8.

[8] A.A. McConnell, M.A. Eastwood, W.D. Mitchell, "Physical characteristics of vegetable foodstuffs that could influence bowel function," J. Sci. Food Agric., vol. 25, pp. 1457-1464, December 1974 https://doi.org/10.1002/jsfa.2740251205.

[9] M.J.Y. Lin. "Certain functional properties of sunflower meal products," J. Food Sci., vol. 39, pp. 368-370, March 1974 https://doi.org/10.1111/j.1365-2621.1974.tb02896.x.

[10] J.M. Fuentes-Alventosa, G. Rodríguez-Gutiérrez, S. JaramilloCarmona, J.A. Spejo-Calvo, R. Rodríguez-Arcos, J. FernándezBolaños, R. Guillén-Bejarano, A. Jiménez-Araujo, "Effect of extraction method on chemical composition and functional characteristics of high dietary Fiber powders obtained from asparagus byproducts," Food Chem., vol. 113, pp. 665-671, March 2009 https://doi.org/10.1016/j.foodchem.2008.07.075.

[11] A. Mrabet, G. Rodríguez-Gutierrez, R. Guillen-Bejarano, R. Rodríguez-Arcos, A. Ferchichi, M. Sindic, A. Jimenez-Araujo, "Valorization of Tunisian secondary date varieties (Phoenix dactylifera L.) by hydrothermal treatments: New fiber concentrates with antioxidant properties," LWT - Food Sci. Technol., vol. 60, pp. 518 524, January 2015. https://doi.org/10.1016/j.lwt.2014.09.055.

[12] M. Dubois, K.A. Gilles, G.K. Hamilton, P.A. Rebers, F. Smith. Colorimetric method for determination of sugars and related substances. Anal Chem., vol. 28, pp. 350-356, March 1959. https://doi.org/10.1021/ac60111a017.

[13] J.M. Morillas-Ruíz, J.M. Delgado-Alarcón, “Análisis nutricional de alimentos vegetales con diferentes orígenes: Evaluación de capacidad antioxidante y compuestos fenólicos totales," Nutr. Clin. Diet. Hosp., vol. 32, no. 2, pp. 8-20, 2012.

[14] R. Rodríguez, S. Jaramillo, G. Rodríguez, J.A. Espejo, R. Guillén, J. Fernández-Bolaños, A. Heredia, A. Jiménez, "Antioxidant activity of ethanolic extracts from several asparagus cultivars", J. Agr. Food Chem., vol. 53, pp. 5212-5217, June 2005. https://doi.org/10.1021/jf050338i.

[15] A. Nsren, "Etude comparative des procédés de séchage couplés à la texturation par Détente Instantanée Contrôlée DIC, en termes de cinétique et de qualité nutritionnelle. Applications à la valorisation des déchets agro-industriels," Ph.D. dissertation (in French), La Rochelle Univ, La Rochelle, France, 2010.

[16] A. Mrabet, R. Rodríguez-Arcos, R. Guillén-Bejarano, N. Chaira, A. Ferchichi, A. Jiménez-Araujo, "Dietary Fiber from Tunisian Common Date Cultivars (Phoenix dactylifera L.): Chemical Composition, Functional Properties, and Antioxidant Capacity,". J. Agr. Food Chem., vol. 60, pp. 3658-3664, April 2012. https://doi.org/10.1021/jf2035934.

[17] A. Abdul-Hamid, Y.S. Luan, "Functional properties of dietary fiber prepared from defatted rice bran," Food Chem., vol. 68, pp. 15-19, January 2000. http://dx.doi.org/10.1016/S0308-8146(99)00145-4.

[18] L. Prosky, N.G. Asp, T.F. Scheweizer, J.W. DeVries, I. Furda, "Determination of insoluble and soluble, and total dietary Fiber in foods and food products: interlaboratory study," J Assoc Off Anal Chem., vol. 71, pp. 1017-1023, September-October 1988.

[19] USDA. (September 2020). National Nutrient Database for Standard Reference. Database Ressources of the United States Department of Agriculture. Available: http://ndb.nal.usda.gov/ndb/foods

[20] P. Wachirasiri, S. Julakarangka, S. Wanlapa, "The effects of banana peel preparations on the properties of banana peel dietary Fiber concentrate," Songklanakarin J. Sci. Technol., vol. 31, no. 6, 605-611, January, 2010.

[21] H.N. Rabetafika, B. Bchir, M. Aguedo, M. Paquot, C. Blecker, "Effects of Processing on the Compositions and Physicochemical Properties of Fiber Concentrate from Cooked Fruit Pomaces," Food Bioproc. Tech. 
vol. 7, pp. 749-760, March 2014. https://doi.org/10.1007/s11947-0131073-0.

[22] C. Borchani, S. Besbes, M. Masmoudi, C. Blecker, M. Paquot, H. Attia Influence of oven-drying temperature on physicochemicaland functional properties of date fiber concentrates. Food Bioproc. Tech., vol. 5, no. 1541-1551, July 2012. https://doi.org/10.1007/s11947-011$0549-\mathrm{z}$.

[23] Z. Lou, H. Wang, D. Wang, Y. Zhang, "Preparation of inulin and phenols-rich dietary Fiber powder from burdock root," Carbohydrate Polymers., vol. 78, pp. 666-671, November 2009. https://doi.org/10.1016/j.carbpol.2009.05.029.

[24] C.C. Tsen, W. Eyestone, J.L. Weber, "Evaluation of the quality of cookies supplemented with distillers' dried grain flour," J. Food Sci., vol. 47, no. 2, pp. 684-685, March 1982. https://doi.org/10.1111/j.1365-2621.1982.tb10156.x.

[25] F.A. Masood, B. Sharma, G.S. Chauhan, "Use of apple as a source of dietary fiber in cakes," Plant Food Hum. Nutr., vol. 57, pp. 121-128, March 2002. https://doi.org/10.1023/A:1015264032164.

[26] R. Kaur, M. Kaur, "Microstructural, physicochemical, antioxidant, textural and quality characteristics of wheat muffins as influenced by partial replacement with ground flawseed," LWT - Food Sci. Technol., $\begin{array}{llll}\text { vol. } 91, \quad \text { pp. 278-285, May } 2018 . & \end{array}$ https://doi.org/10.1016/j.lwt.2018.01.059.

[27] V. Baldi, L. Little, E.E. Hester, "Effect of kind proportion of flour components and of cellulose level on cake structure," Cereal Chem., vol. 42, pp. 462-465, 1965.

[28] D.H. Donelson, J.T. Wilson, "Effect of the relative quantity of flour fractions on cake quality," Cereal Chem., vol. 37, pp. 26-28, 1960.

[29] M. Sowmya, T. Jeyarani, R. Jyotsna, D. Indrani, "Effect of replacement of fat with sesame oil and additives on rheological, microstructural, quality characteristics and fatty acid profile of cakes," Food Hydrocolloids, vol. 23, pp. 1827-1836, October 2009. https://doi.org/10.1016/j.foodhyd.2009.02.008.

[30] Y. Pomeranz, D. Meyer, W. Seibel, "Wheatrye and rye dough and bread studied by scanning electron microscopy," Cereal Chem., vol. 61, pp. 53-59, 1984.

[31] J. Gao, F. Han, X. Guo, X. Zeng, S. Mason, M. Lbrennan, C.S Abrennan, "Image Analysis of the Sugar-reduced Muffin Formulated with Stevianna ${ }^{\circledR}$ or Inulin as a Sugar Replacer," Grain Oil Sci. Technol., vol. 1, no. 2, pp. 63-71, April 2018. https://doi.org/10.3724/SP.J.1447.GOST.2018.18043.

[32] J.K. Kim, H.J. Lee, H.S. Lee, E.J. Lim, J.Y. Imm, H.J. Suh, "Physical and sensory characteristics of Fiber-enriched sponge cake made with Opuntia humifusa," LWT - Food Sci. Technol., vol. 47, pp. 478-484, July 2012. https://doi.org/10.1016/j.lwt.2012.02.011.

[33] P. Ambigaipalan, F. Shahidi, "Date seed flour and hydrolysates affect physicochemical properties of muffin," Food Biosci., vol. 12, pp. 5460, December 2015. https://doi.org/10.1016/j.fbio.2015.06.001.

[34] T.M. Lu, C.C. Lee, J.L. Mau, S.D. Lin, "Quality and antioxidant property of green tea sponge cake," Food Chem., vol. 119, pp. 10901095, April 2010. https://doi.org/10.1016/j.foodchem.2009.08.015.

[35] N. Vergara-Valencia, E. Granados-Perez, E. Agama-Acevedo, J. Tovar, J. Ruales, L.A. Bello-Perez, "Fiber concentrate from mango fruit: characterization, associated antioxidant capacity and application as a bakery product ingredient," LWT - Food Sci. Technol., vol. 40, pp. 722-729, May 2007. https://doi.org/10.1016/j.1wt.2006.02.028.

[36] C. Talens, S. Alvarez-Sabatel, Y Rios, R. Rodriguez, "Effect of a new microwave-dried orange fiber ingredients vs. a commercial citrus fiber on texture and sensory properties of gluten-free muffins," Innov. Food Sci. Emerg. Technol., vol. 44, pp. 83-88, December 2017. https://doi.org/10.1016/j.ifset.2017.07.011. 